\title{
LEGIBILITY
}

A major purpose of the Technical Information Center is to provide the broadest dissemination possible of information contained in DOE's Research and Development Reports to business, industry, the academic community, and federal, state and local governments.

Although a small portion of this report is not reproducible, it is being made available to expedite the availability of information on the research discussed herein.

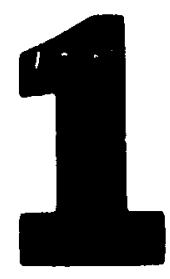


LA-UR -90-35;

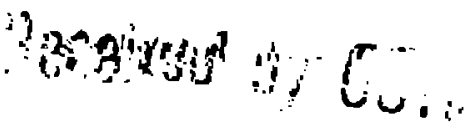

Fith 9 ig

\title{
DISCLAIMER
}

\begin{abstract}
This report was prepared as an account of work sponsored by un agency of the Uniled Stutes Government. Neither the I/nited Stales (iuvernment nor any agency thireof, nor any of their empluyees, mikes any warranty, express or implied, ("r assumes any legal liabilily or responsiholity for the accuracy, compleleness, or usefulness of iny information, apparalus, product. of process disclosed, or repiesents that its use would nol infringe privalely owned rights Reference herein to any specific commercial proxlucl, pricess, ur service hy trade name. Irademark. manufacturer, or wherwise dies not necessurily consillute ur umply its endorsement, recommendatuon, or fuvoring hy the Ilnited Stales fiovernment or any agency thereof The virws and upinusns of authors expressed herein dio not necessiarly state or reflect thuse uf the Inited Siates (iovernment or any inency thereof
\end{abstract}

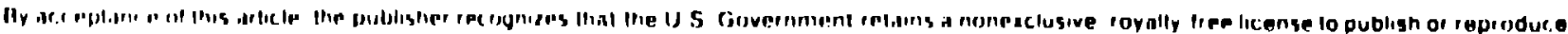

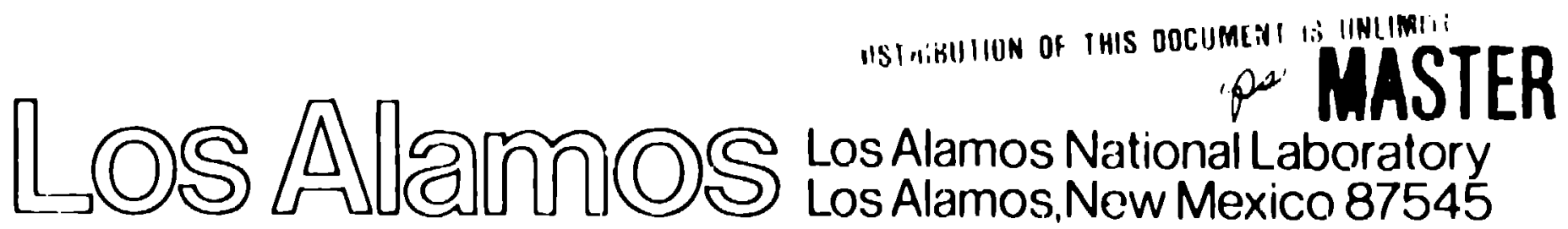


'TWS-EES-5-1-90-05

WBS 1.2.3.4.1.5.1

QA: Level 3

\section{Simulation of Heat Transfer in the Unsaturated Zone}

\section{Gcorge Zyvoloski}

\section{Introduction}

It is well known that heat transfer can play an important roll in fluid flow near the emplacement site of high-level nuclear waste (Pruess and Wang, 1987). Heat transfer effects on far-field flow have received much less attention. The effects, though less dramatic than near-ficld effects, nevertheless can be important in understanding net moisture Auxcs above the repository zone. Weeks (1987) described two wells at the Yucca Mountain site that produce air at high flow rates in winter. It was postulated that convection in the unsaturated zone was responsible for this movement. If this is so, then the convection could provide a mechanism for drying the rock above the repository zone and thus provide a buffer for heavy rainfall events. In addition, the convection would increase the movement of gaseous radionuclides such as ${ }^{14} \mathrm{CO}_{2}$, tritiated water vapor, and ${ }^{120} \mathrm{l}$ (Weeks, 1987). Because of the complexity of the problem, numerical models were required to calculate gas flow and vapor transport at the site.

Kipp (1987) previously modeled this problem using the code HST3D). This cocle represents the flow of a single-phase fluid with both heat-and mass-transfer effects included. Wuter density and partial pressure effects are accounted for by the virtual temperature method [List (1966)]. In this paper, the problem was simulated using the code FrillMN, a finite-element heat-and mass-transfer code being developed for the Yurca. Mounlain Project at Los Alamos National laboratory. Besides aiding in the understanding of the problem described above, the work described in this paper was done in preparation of the upeoming problem to be formulated for the Performance Assessment ('alculation Fixerrise (PA('F).

\section{'The Model}

FEHMN models the flow of heat and mass in a saturated or unsaturated porous media. The conservation of mass is expressed by the equation 


$$
\frac{\partial .4 m}{\partial t}+\bar{\nabla} \cdot \bar{F}_{m}+q_{m}=0
$$

where the mass per unit volume, $A_{m}$, is given by

$$
A_{m}=\phi\left(S_{v} \rho_{v}+S_{\ell} \rho_{\ell}\right)
$$

and the mass flux $\bar{F}_{m}$ is given by

$$
\bar{F}_{m}=\rho_{v} \bar{V}_{v}+\rho_{l} \bar{V}_{l}
$$

Here $\phi$ is the porosity of the rock matrix, $S_{v}$ and $S_{\ell}$ are the phase saturations, $\rho_{v}$ and $p_{\ell}$ are the phase densities, and $\bar{V}_{v}$ and $\bar{V}_{l}$ are the phase velocities. The subscripts $v$ and $\ell$ refer to the vapor and liquid phases respectively. The source or sink terms are represented by $q_{m b}$. 'The conservation of energy is expressed by the equation

$$
\frac{\partial A_{e}}{\partial t}+\bar{\nabla} \cdot \bar{F}_{e}+q_{e}=\mathbf{0}
$$

where the energy per unit volume is given by

$$
A_{e} \because(1-\phi) \rho_{r} u_{r}+\phi\left(S_{v} \rho_{v} u_{v}+S_{l} \rho_{\ell} u_{\ell}\right),
$$

and the energy fux $F_{e}$ can be written as

$$
\text { Fe } \rho_{v} h_{v} \bar{V}_{v}+\rho_{\ell} h_{\ell} \bar{V}_{l}+K \Gamma T \text {. }
$$

Hlere $T$ is the lemperature; $u_{r}, u_{v}$, and $u_{\ell}$ are specific internal energies; and $h_{v}$ and he are specific enthalpies. In addition to the subseripts previously mentioned, $r$ refers to the rock matrix. 'I'he energy contributed from sources is given by $q_{e} . K$ is the eflertive thermal conductivity. 'This parameter is difficult to estallish as it depends not only un rock type and porosity, but also on the saturation value. A major assumption used in lhe colergy equation is thermal equilibrium between the phases and the rock. 'The slow flow rates justify this assumption. In addition to the total mass and renergy conservation equations, an air conservation equation is also required. 'This equation may be writlen as 


$$
\frac{\partial A_{\mathrm{c}}}{\partial t}+\bar{\nabla} \cdot \bar{F}_{c}+q_{c}=0
$$

where the air mass per unit volume, $A_{c}$, is given by

$$
A_{\mathrm{c}}=\phi\left(S_{\mathrm{v}} \eta_{v} \rho_{\mathrm{v}}+S_{\ell} \eta_{\ell} \rho_{\ell}\right)
$$

and the air mass flux is given by

$$
\bar{F}_{c}=\rho_{v} \eta_{v} \bar{V}_{v}+\rho_{\ell} \eta_{l} \bar{V}_{l}
$$

where $\eta_{v}$ and $\eta_{\ell}$ are the mass fractions of air in the vapor and liquid phases respectively. The source term for air is given by $q_{c}$. For the present analysis, we have neglected vaporair diffusion and Knudsen effects, which can be important in other applications. Darcy's law provides the momentum equations to complete the description of the mass and energy flows:

$$
\bar{V}_{v}=\frac{k R_{v}}{\mu_{v}}\left(\bar{\nabla} P_{v}-\rho_{v} \bar{g}\right)
$$

and

$$
v_{\ell} \cdots R_{\mu_{\ell}}^{k R_{\ell}}\left(\Gamma P_{l} \quad \rho_{\ell} g\right)
$$

Ilere $k$ is the intrisic rock permeability, $R_{v}$ and $k$, the relative phase permeabilities, $\mu_{\nu}$ and $\mu_{\ell}$ the phase viscosities, $\rho_{\nu}$ and $\rho_{\ell}$ the phase pressures, and $g$ is the acceleration of gravity. The phase pressures are related by the capillary pressure, Prap:

$$
P_{v}: P_{\ell}+P_{\text {rap }}
$$

Substituting the velocity expression into the conservation eduations, a set of diffusionlike equations is obtained. It is these equations that are solved in FFHMN.

The conservation equations contain many terms that require constitutive relation ships. The rules governing the mixtures of air and water vapor will not be rovered here, the reader is referred to Zycoleski (1988) for details. 'The water properties themerelves 
are obtained by rational polynomial fits to National Bureau of Standards (NBS) stcarn table data. Air properties were represented by polynomials and the perfect gas law. The capillary pressure and the relative permeabilities are usually strongly nonlinear functions of the saturation. In this study, however, we allow only the gas phase to flow, so at least for now, the functional dependence of the capillary pressure and the relative permeabilities are irrelevant.

The conservation equations are discretized with a nodal-based finite-element method and are formulated with an implicit time-stepping scheme. A Preconditioned Conjugate Gradient meihod is used to solve the equations. For details on the numerical procedures, the reader is referred to $Z$ yvoloski (1988).

The code also has provisions to model tracer transport with velocities provided by the flow portion of the code. In this study, no transport calculations were made. The reader will find a brief description of the transport capability of FEHMI in $\mathrm{Z}_{\mathbf{y}}$ voloski (1988).

\section{Simulation Studies}

Weeks (1987) presents a cross section of the region of interest in Yucca Mountain. This is reproduced in Fig. 1. Evident in the figure are the two wells, UZ-6 and UZ-6S. These wells have been observed to flow at $3 \mathrm{~m} / \mathrm{s}$ in the winter. With these air velocities and using the observed exil air temperature of $18^{\circ} \mathrm{C}$, UZ-6 and UZ-6S were discharging $560 \mathrm{l} / \mathrm{d}$ and $125 \mathrm{l} / \mathrm{d}$ respectively of water. $A \mathrm{n}$ idealized 2-D model of the shaded region in Fig. 1 is show $n$ in Fig. 2 where the left boundary is the side of the mountain.

The grid in the figure is similar to that used by Kipp (1987). It contains 100 nodes. 'The input parameters for the 2-1) calculation are showli in 'Table 1 . The boundary temperatures shown in Table I were srason averages and were taken from Kipp.

Figure 3 shows the result of the 2-I) simulation without a borehole. The pattern of fow for summer and winter are similar to those oblained by Kıpp. The maximum velocities obtained by Kipp were several times larger than those obtained in this study. The spring and fall velocities were at least an order of magnitude smaller than summer and winter velocities. 'The now patterns for spring and fall were qualitatively different than Kipp's results. 'These seasons produce pressure distributions aiong the mountain face similar (o) 


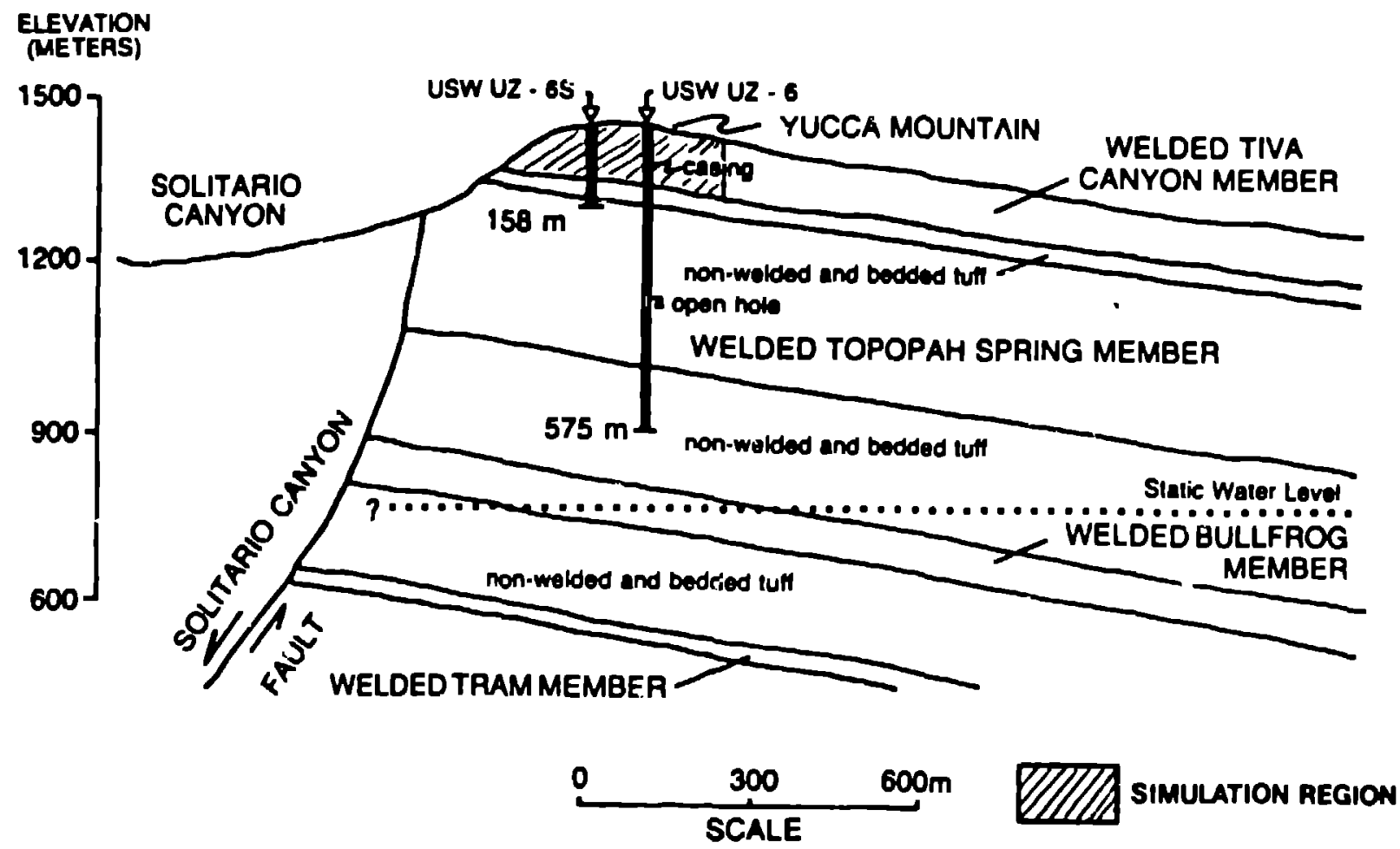

Fig. 1. Cross section of Yucca Mountain in the vicinity cf wells UZ-6 and UZ-6S. (Reprinted with permission from AGU monography 42.)

Specified T,P

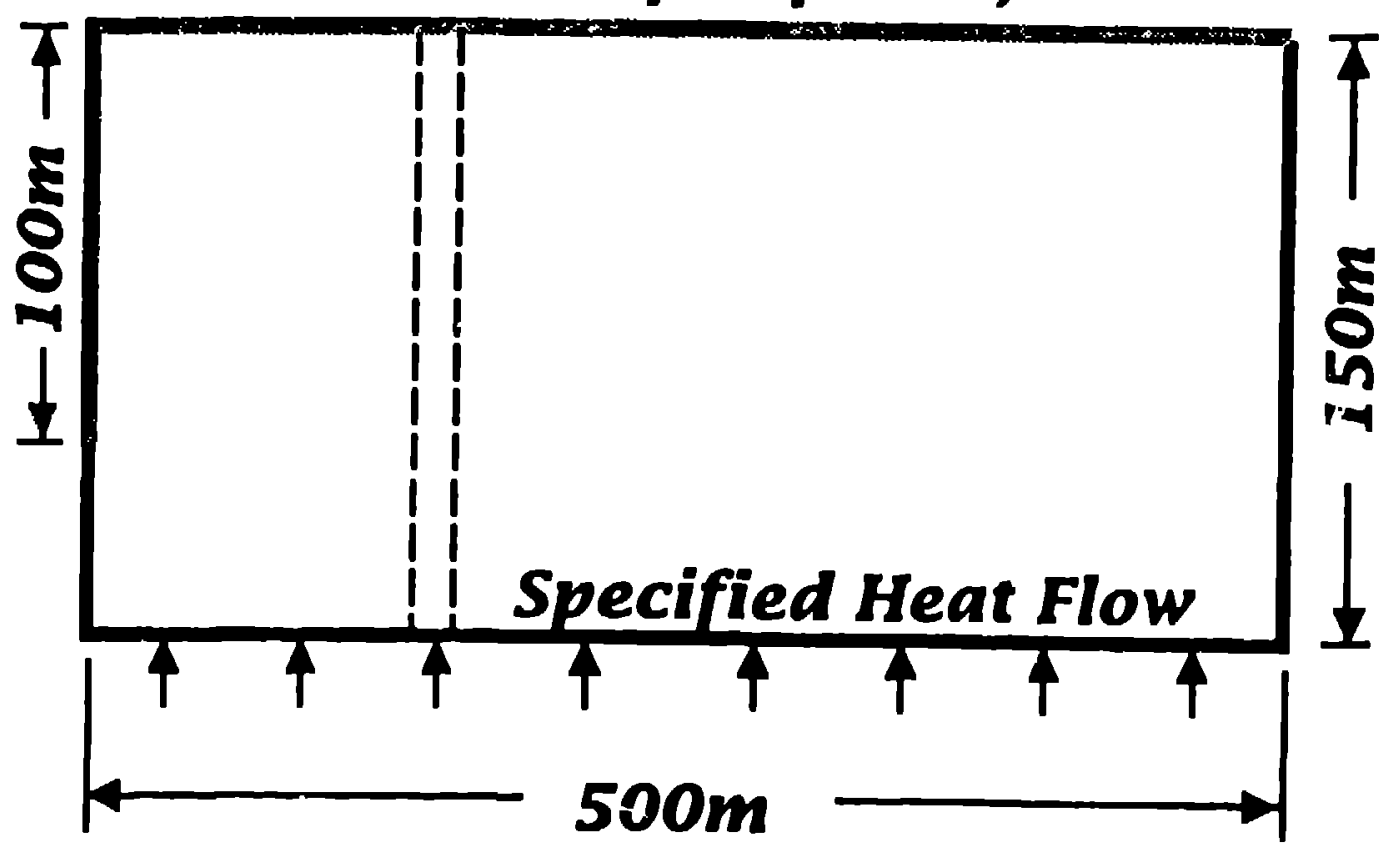

Fig. 2. Idealized 2-1) model of Yurca Mountain for numerical computations. 

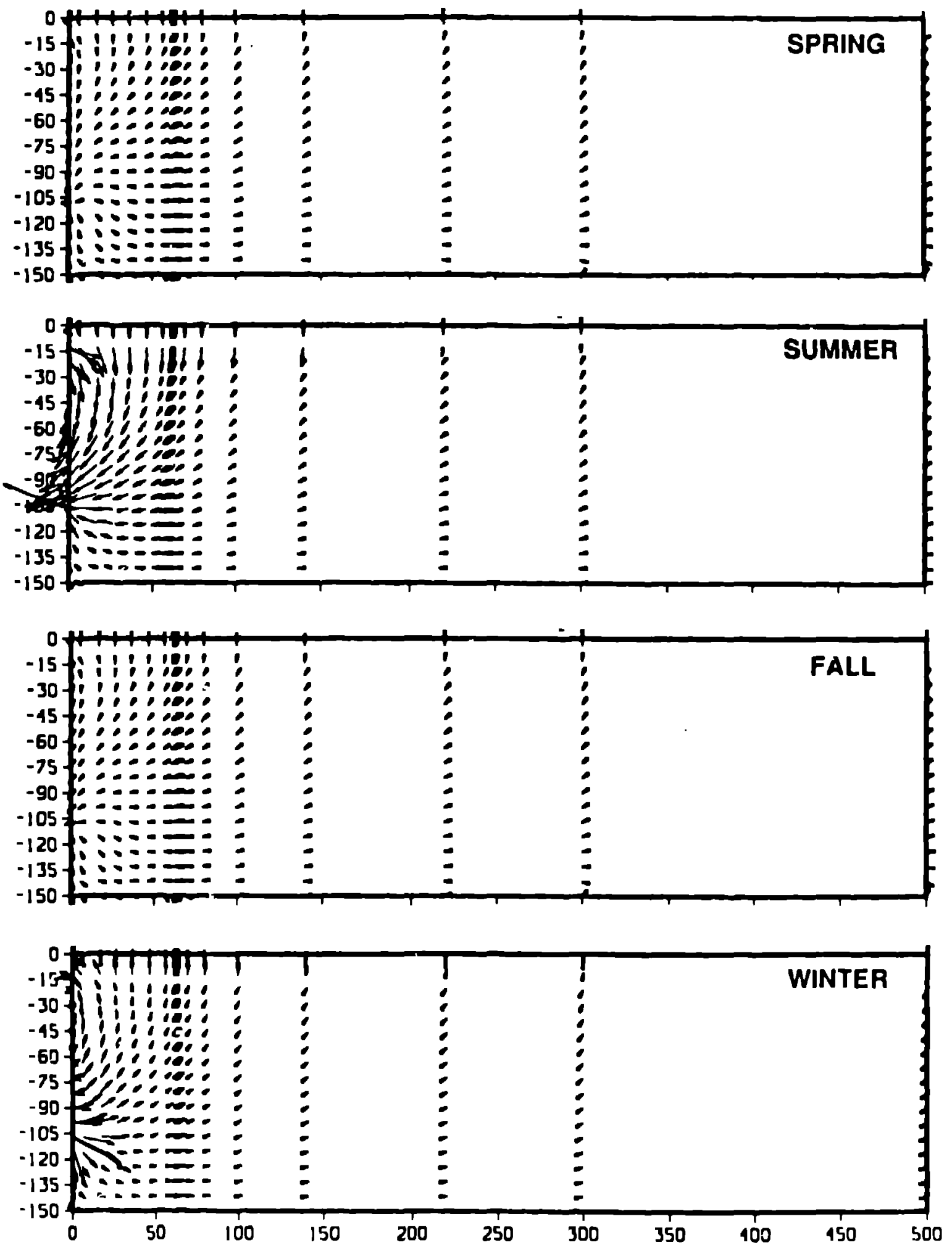

Fig. 3. Velocity vector field for 2.1$)$ simulation with no wellbore. A vector $50 \mathrm{~m}$ long is equivalent to $10^{5} \mathrm{~m} / \mathrm{s}$. 


\section{TABLE I. Input Parameters for 2-D Calculation}

\section{Geometry:}

Reservoir Size: $500 \mathrm{~m}(\mathrm{x}), 150 \mathrm{~m}(\mathrm{y})$

20 nodes $x$ direction (graded)

20 nodes $y$ direction (craded)

\section{Rock Properties:}

\begin{tabular}{lll} 
& \multicolumn{1}{c}{ Soil Layer } & \multicolumn{1}{c}{ Welded Tuff } \\
& & \\
Permeability & $1 . e-11 \mathrm{~m}^{2}$ & $1 . e-10 \mathrm{~m}^{2}$ \\
Porosity & 0.25 & 0.10 \\
Specific Heat & $1000 . \mathrm{kj} / \mathrm{kg} / \mathrm{K}$ & $1000 . \mathrm{kj} / \mathrm{kg} / \mathrm{K}$ \\
Density & $2000 . \mathrm{kg} / \mathrm{m}^{3}$ & $1300 . \mathrm{kg} / \mathrm{m}^{3}$ \\
Thermal Conductivity & $0.75 \mathrm{~W} / \mathrm{m} / \mathrm{K}$ & $2.25 \mathrm{~W} / \mathrm{m} / \mathrm{K}$
\end{tabular}

Fluid Properties:

Water: Given by rational polynomial fits to NBS steam table data

Air: Polynomial fits perfect gas law, Henry's law

\section{Boundary Conditions:}

Specified temperature and pressure on surface $A$

Spring: $\mathrm{T}=20^{\circ} \mathrm{C}, \mathrm{p}=0.085 \mathrm{Mpa}+$ hydrostatic

Summer: $\mathrm{T}-30^{\circ} \mathrm{C}, \mathrm{p}-0.085 \mathrm{Mpa}+$ hydrostatic

Fall: 'T : $20^{\circ} \mathrm{C}, \mathrm{p} \quad 0.085 \mathrm{Mpa}+$ hydrostatic

Winter: $\mathrm{T}-10^{\circ} \mathrm{C}, \mathrm{p}-0.085 \mathrm{M}$ pa $\nmid$ hydrostatic

Ileat Flux $0.075 \mathrm{~W} / \mathrm{m}^{2}$ on surface $B$

No fluid or heat fow on surface $C$

\section{Initial Conditions:}

Pressure is hydrostalic

Temperature varies as $0.03^{\circ} \mathrm{k} / \mathrm{m}$

Saturation-0.1 (irreducible)

these inside the mountain. Small differences in density, resulting from the different ways in which the saturated air densities are calculated, could produce the different character of How in the two studies. 'This discrepancy is currently being investigated. The temperature contemers are given in lig. 4. The contenurs reflect the seasomal temperature boundary conditions. The small hump on the $\mathrm{T} 24^{\circ} \mathrm{C}$ c contour is a numerical artifact of the small 
zoning in that region. An additional 2-D model run was made with a crude model of a wellbore the size of UZ-6. It was placed $60 \mathrm{~m}$ from the left boundary. While it is difficult to represent a wellbore in the 2-D cartesian grid (we are averaging arross the mountain), we can still get some idea of the induced upward velocity due to the implacement of a well. ['sing the expected $3-\mathrm{m} / \mathrm{s}$ wellbore velocity, appropriate air properties, $1.8 \mathrm{~Pa} / \mathrm{m}$ pressure drop for turbulent flow [reported by Weeks (1987)], and equivalent darcy permeability of $2 \times 10^{-5} \mathrm{~m}^{2}$ was obtained. This large permeability produced numerical difficulties (i.e., smaller time steps) so $10^{-6}$ was used instead. The seasonal velocity vector plots are presented in Fig. 5. In addition to the increased velocities in the wellbore region, the wellbore appears to curtail vapor movement interior to the wellbore. Maximum velocity occurred in the wellbore was $10^{-2} \mathrm{~m} / \mathrm{s}$ upward flow in the winler. If the permeability were increased to the proper value, this velocity would likely increase to order $10^{-1} \mathrm{~m} / \mathrm{s}$, sti!l an order of magnitude slower than the observed rate. Temperature changes induced by the wellbore were only slight and are not shown.

The 2-D model lacks information on the lateral flow from the side of Yucca Mountain as well as any 3-D flow effects. To help understand these phenomena, a simple 3-D representation of the region around wells UZ-6 and UZ-6S was constructed. This is shown in Fig. 6. There were 3740 nodes in this problem: 20 in the $x$ direction, 11 in the $y$ direction, and 17 in the $z$ direction. The boundary and initial conditions are the same as for the 2-D calculations with the exception that the pressure and temperalure boundary conditions are applied to three sides and the top instead of just the left face and the top as in the 2-D calculations. The results for the 3-D run without a wellbore is presented in Fig. 7. Shown in the figure is a vertical slice of Yucca Mountain in the center of the calculation region. Comparing Fig. 7 with Fig. 3, it can be secn that the 3-D results are qualitatively different than the 2 -I) results. While the 2 -D results show much of the gas exiting the side of the mountain during the spring, summer, and fall, the 3-D results show the flow going toward the center of the mountain. 'The temperature results given in Irig. 8 show smoother contours than the corresponding 2-I) case (even taking into account the differing scales of the two figures). Introducing a wellbore the size of UZ-6 into the grid (with a permeability of $10^{7} \mathrm{~m}^{2}$ ) produced some very interesting results. The results are 

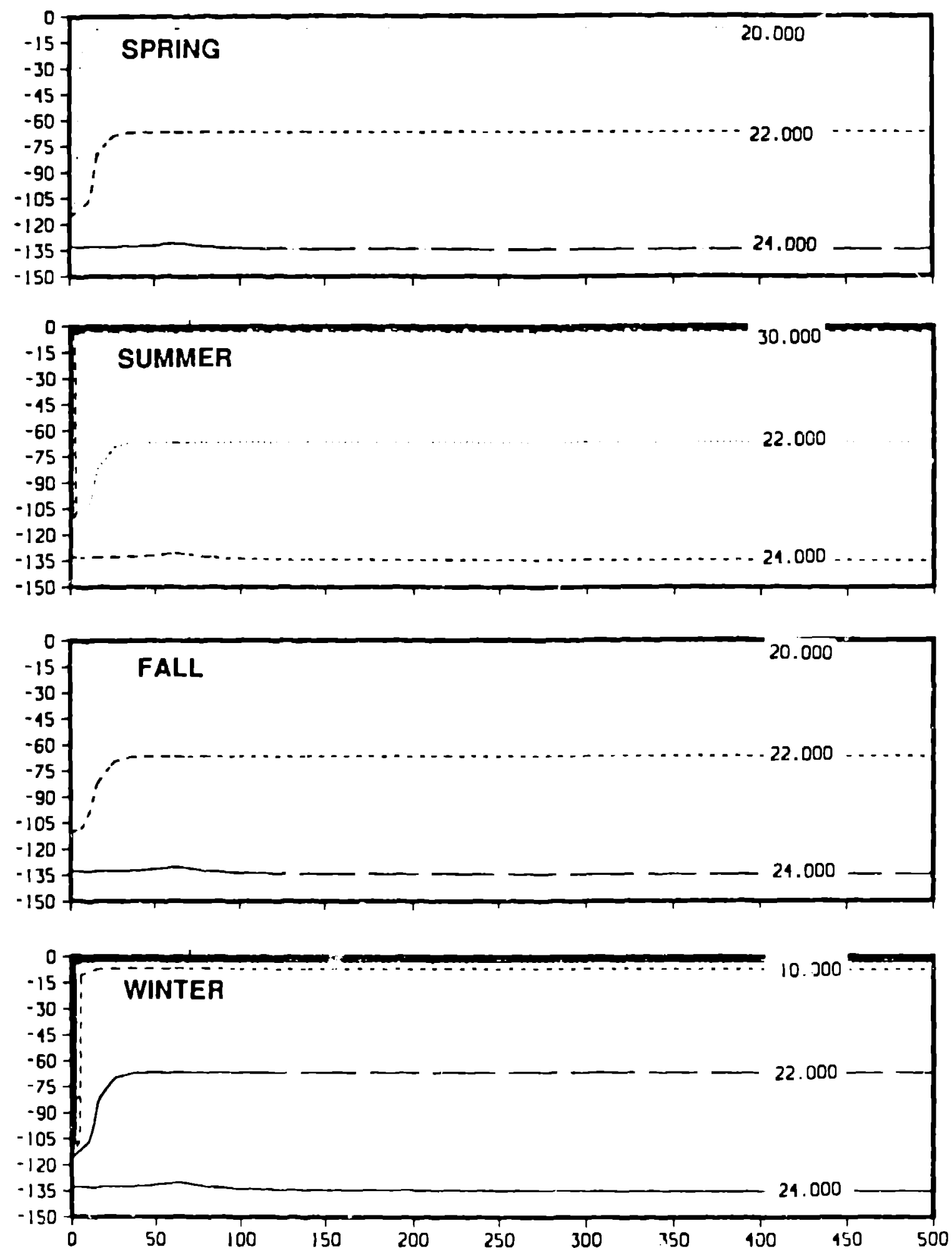

Fig. 4. Temperature contours for the 2 D simulation with no wellbore. 

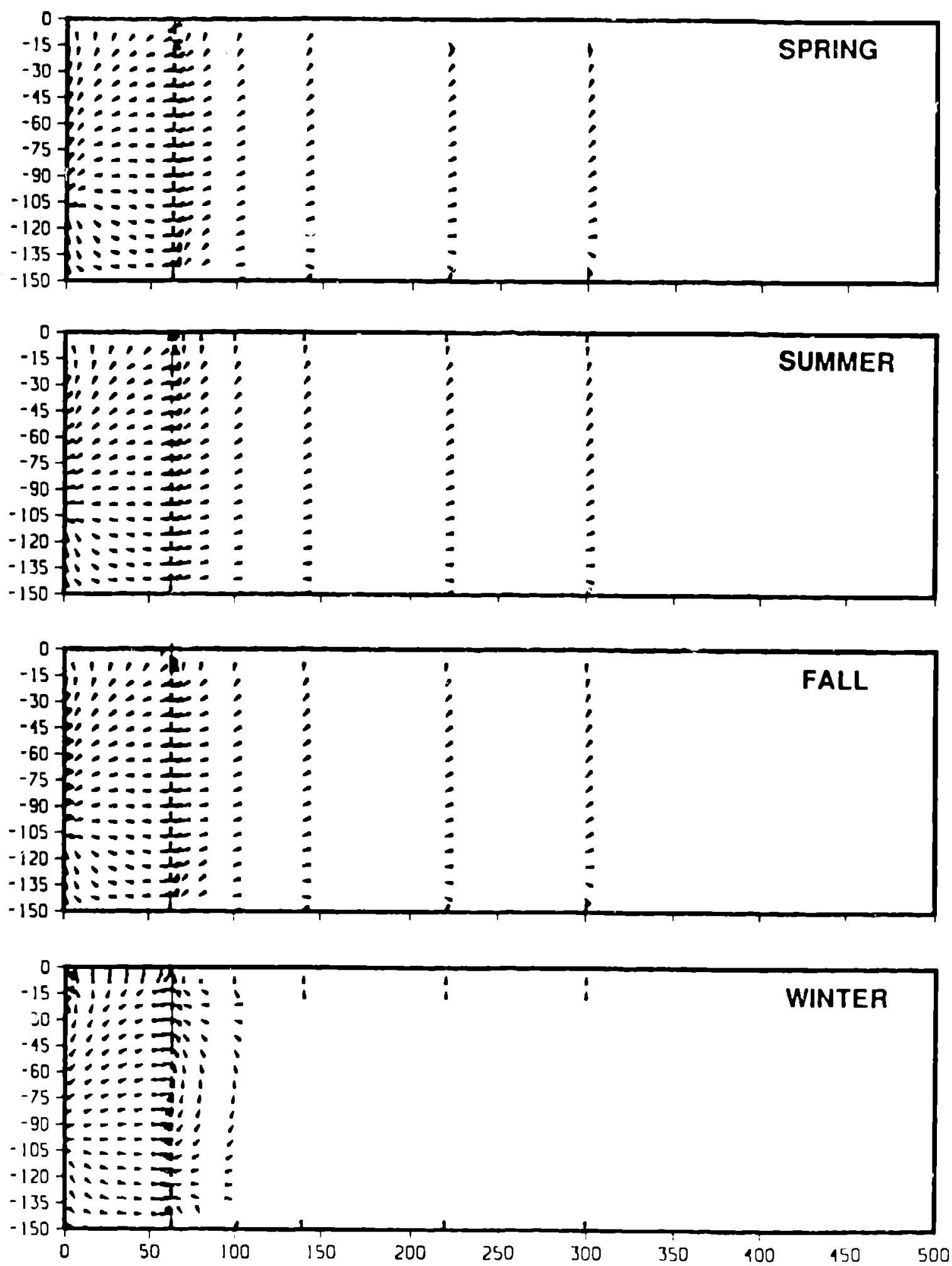

Fig. 5. Velocity vector field for the $2-1$ ) simulation with a wellbore. A vector $50 \mathrm{~m}$ long is equivalent to $10^{3} \mathrm{~m} / \mathrm{s}$. 


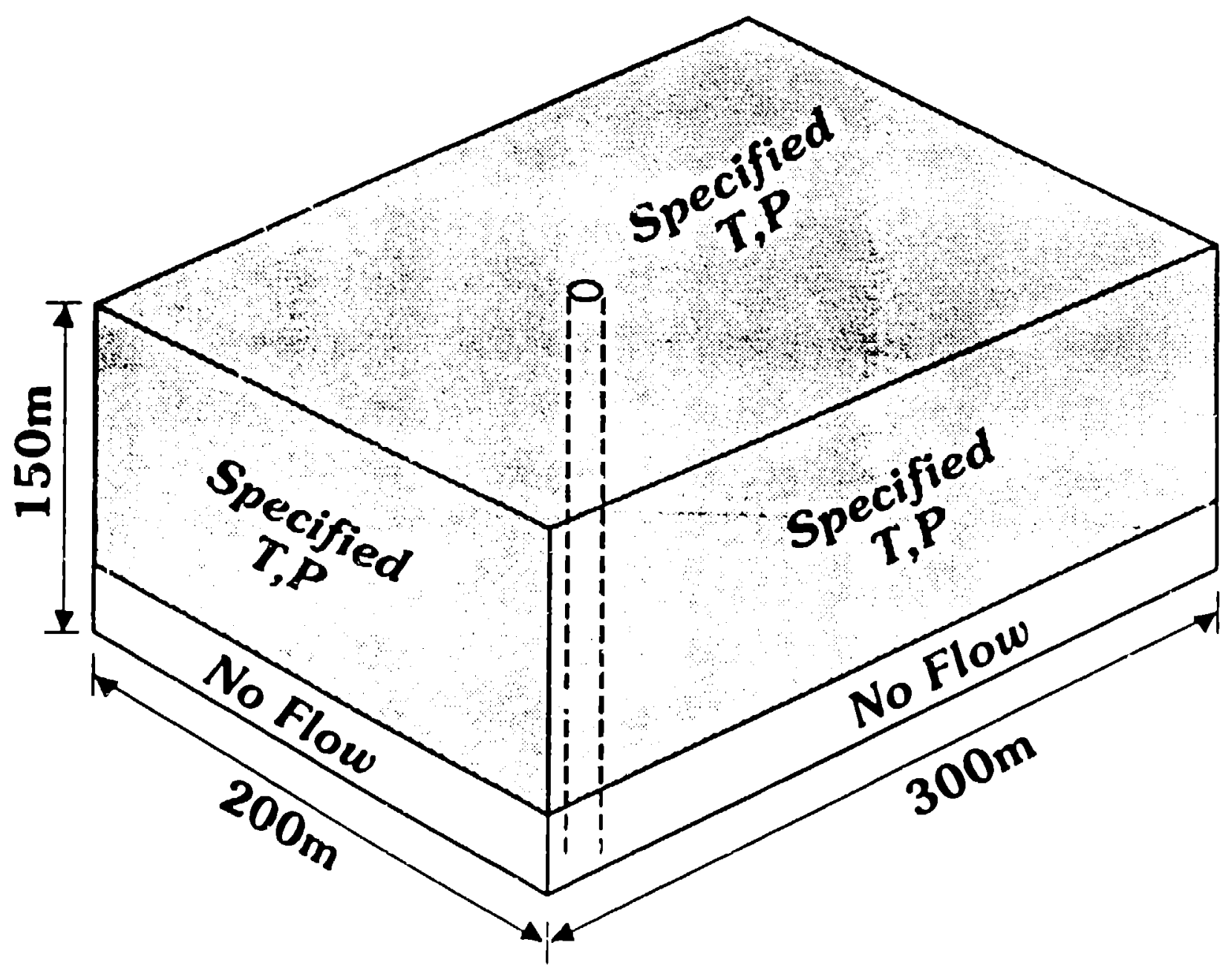

Fig. 0. Idealized: I) model of Puca Mountain for numerical computations. 

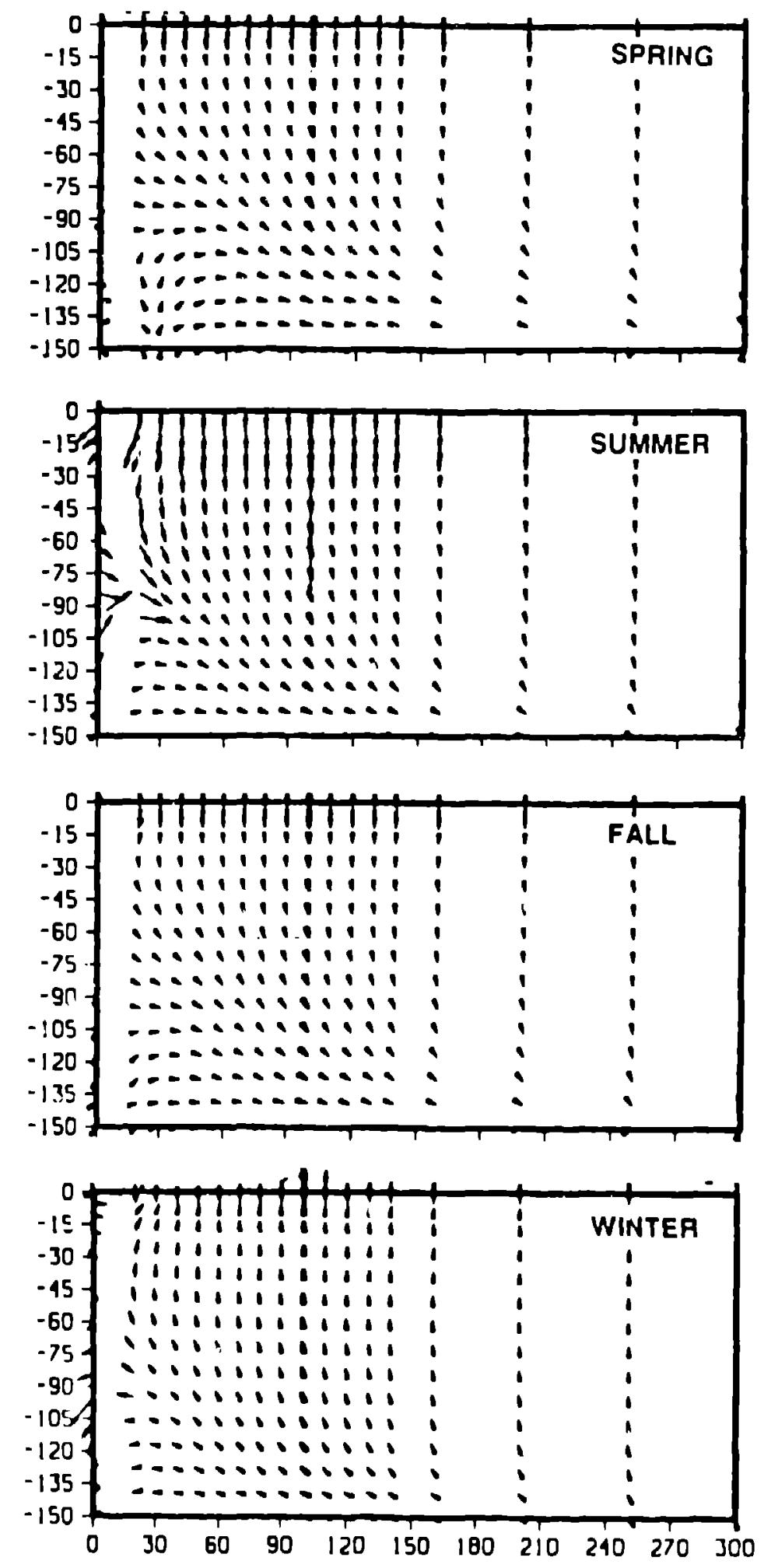

Fig. 7. Velocity vertor field for an $x \quad z$ slice in renter of simulation region. A vector $50 \mathrm{~m}$ long is equivalent to $10^{5} \mathrm{~m} / \mathrm{s}$ 

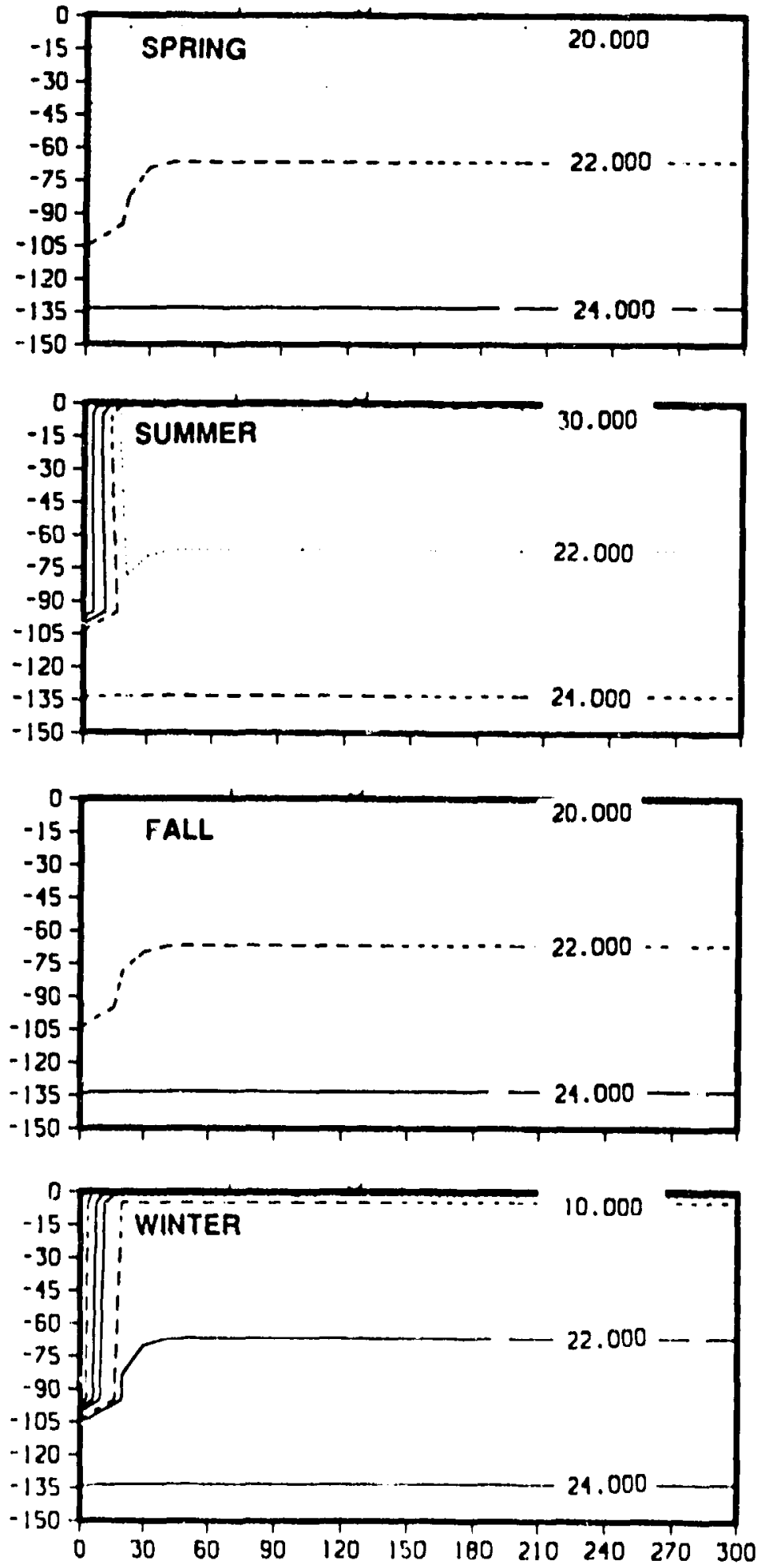

Fig. 8. Temperature contours for the 3.1) simulation. 

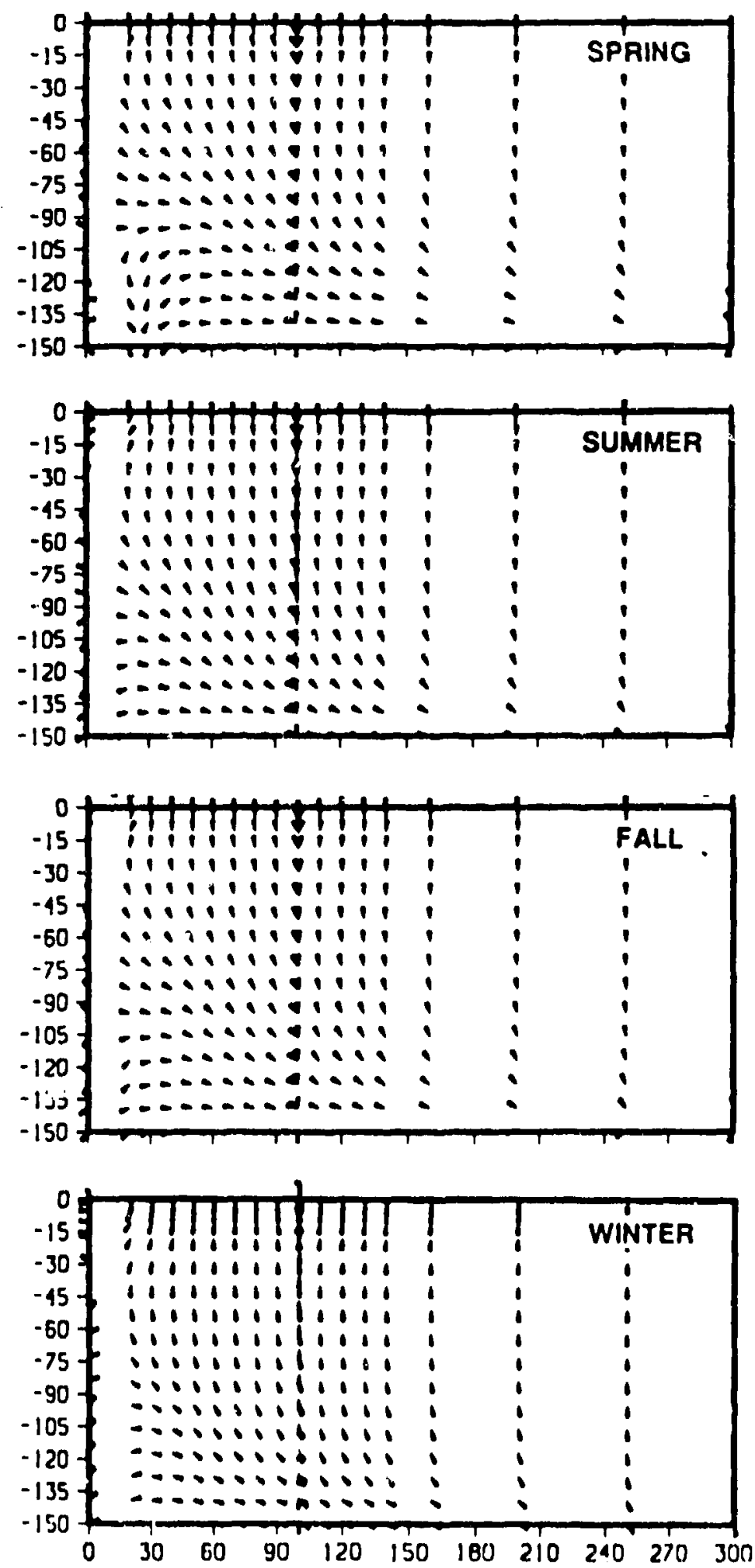

Fig. 0. Velecity vertor field for an $x=z$ slice in the renter of the simmlation region. $\Lambda$ vector $50 \mathrm{~m}$ long is equivialent to $10^{2} \mathrm{~m} / \mathrm{s}$. 
presented in Fig. 9 show that the effect of the wellbore was quite dranatic. Velucities in the wellbore during winter were $2 \times 10^{-3} \mathrm{~m} / \mathrm{s}$. As ivith the 2-1) simulation, a smaller permeability was used for the numerical calculations. Increasing the permeability to the wellbore value of $2 \times 10^{-5}$ would likely produce velocities of $\sim 0.5 \mathrm{~m} / \mathrm{s}$. Once again the 3-D flows were qualitatively different than the 2-D flows. As expected, the winter flows were more evenly spread throughout the mountain with the 3- $\mathrm{L}$ model than with the 2-D model.

\section{Remarks}

1. While the runs presented here did not produce the observed fow rates, they did come close. It was noticed that by making the ratio of horizontal-to-vertical permeability larger, more gas would enter the wellbore. This would occur at Yucca Mountain if the wellbores intersected large, nearly horizontal fractures. Simulations of this phenomena are presently being performed.

2. Due to the deep circulation patterns observed in the simulatirn, an expansion of the grid in the vertical direction is warranteri.

3. As the model is capable of simulating multiple-phase now, rainfall can also be included. 'The interaction of convection and moisture movement could be evalualed.

4. Moisture fluxes from the top of Yucca Mountain will be evaluated in the fut tire as well as temperatures inside the well.

5. 'Ihe 3.D) simulation (3 unknowns/node, 3470 nocles, 219 timesteps) took about 50 minutes of CPU time on the CRAY XMI' computer.

\section{Conclusions}

A numerical model capable of describing the fow of heat, mass and air in " variably saturaled porous and fractured media has beren described. Simplified 2.1) and i I) simulations of the gas flow near the wells $11 \%$ a and I:\% (iS were run. 'The 2 I) results matehed those of Kipp, and the 3 I) results provided insight into the real gas flow in Yuera Monn tain. 'The simplified model was net able to clessely match the observed flow in wel! UY, 6.

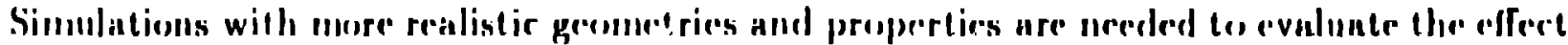
of convertion as a mosisture barrier and a transpourt mechanism for guseous rndionuclides. 


\section{Acknowledgement.}

This work was supported by the The Yucca Mountain Project Office as part of the Civilian Radioactive Waste Management Program. This project is managed by the U. S. Department of Energy, Nevada Operations Office. Nonreferenced information and data can be found in the Los Alamos National Laboratory Notebook TWS-EFS-5/8-88-01.

The sof!ware documented in this report was not verified, validated, or otherwise subjected to the controls of a Yucca Mountain Project Office-approved quality program.

\section{References}

Kinp K. L., Jr., "Effect of Topography on Gas Flow in Insaturated Fractured Rock: Nur, rical Simulation," Proccedings of the Ameriran Geophysical Innion Symposium on Flow and Transport in Lnsaturated Fractured Rock, D. Fvans, and T'. Nicholson., eds., Geophysical Monograph 42, AGU, 1987.

List, R. J., Smithsonian Metcorological Tables, 6th ed., Sinithsonian Institution Press, Washington, D. C., 1966.

Preuss, K., and J. S. Y. Wang, "Numerical Modeling of Isothermal and Nonisothermal Flow in Unsaturated Fractured Rocks," Proccedings of the American Geophysical Union Symposium on Flow and Transport in Unsaturated Fractured Rork, D. Fuans and Y., Nicholson, eds., Geophysical Monograph 42, AGU, 1987.

Wecks, F. P., "Effect of 'Topography on Cias Flow in I'nsaturated Fraclured Rock: Con. cepts and Observations," Proceedings of the American Ciecopysical I'nion Symposium on Flow and 'Trunsport in Unsaturated Fractured Rock, D., Evans, 'T., Nicholson, eds., Geophysical Monograph 42, AGU, 1987.

Zyvoloski, G., "FFHM: Finite Element Heat and Mass Transfer Code," Los Alamos Na. tional leboralory report LA-11224-MS, loss Alamos, NM, 1988. 